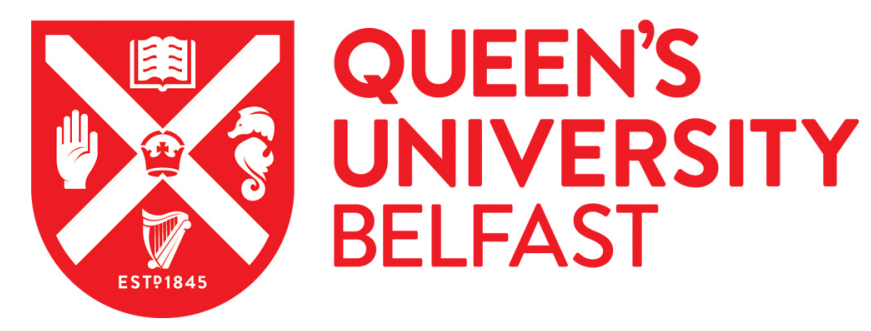

\title{
Processing-property relationships of biaxially stretched poly(L-lactic acid) sheet for application in coronary stents
}

Blair, R., Dunne, N., Lennon, A., \& Menary, G. (2018). Processing-property relationships of biaxially stretched poly(L-lactic acid) sheet for application in coronary stents. Journal of the Mechanical Behavior of Biomedical Materials, 86(Oct 2018), 113. https://doi.org/10.1016/j.jmbbm.2018.06.017

Published in:

Journal of the Mechanical Behavior of Biomedical Materials

Document Version:

Peer reviewed version

Queen's University Belfast - Research Portal:

Link to publication record in Queen's University Belfast Research Portal

Publisher rights

Copyright 2018 Elsevier

This manuscript is distributed under a Creative Commons Attribution-NonCommercial-NoDerivs License

(https://creativecommons.org/licenses/by-nc-nd/4.0/), which permits distribution and reproduction for non-commercial purposes, provided the author and source are cited.

\section{General rights}

Copyright for the publications made accessible via the Queen's University Belfast Research Portal is retained by the author(s) and / or other copyright owners and it is a condition of accessing these publications that users recognise and abide by the legal requirements associated with these rights.

Take down policy

The Research Portal is Queen's institutional repository that provides access to Queen's research output. Every effort has been made to ensure that content in the Research Portal does not infringe any person's rights, or applicable UK laws. If you discover content in the Research Portal that you believe breaches copyright or violates any law, please contact openaccess@qub.ac.uk. 


\section{Author's Accepted Manuscript}

Processing-property relationships of biaxially stretched poly(L-lactic acid) sheet for application in coronary stents

R. Blair, N. Dunne, A. Lennon, G. Menary

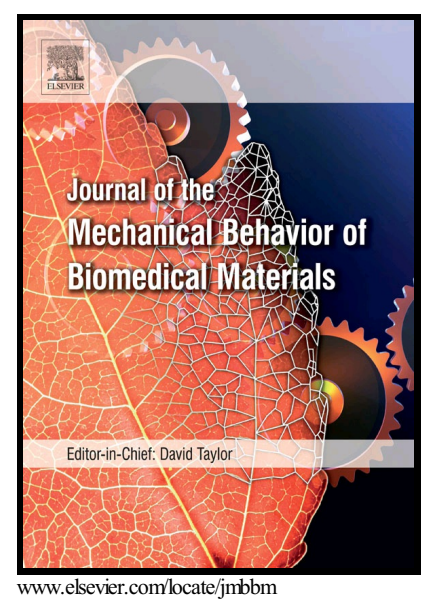

PII: $\quad$ S1751-6161(18)30394-1

DOI: $\quad$ https://doi.org/10.1016/j.jmbbm.2018.06.017

Reference: JMBBM2838

To appear in: Journal of the Mechanical Behavior of Biomedical Materials

Received date: 23 March 2018

Revised date: 28 May 2018

Accepted date: 9 June 2018

Cite this article as: R. Blair, N. Dunne, A. Lennon and G. Menary, Processingproperty relationships of biaxially stretched poly(L-lactic acid) sheet for application in coronary stents, Journal of the Mechanical Behavior of Biomedical Materials, https://doi.org/10.1016/j.jmbbm.2018.06.017

This is a PDF file of an unedited manuscript that has been accepted for publication. As a service to our customers we are providing this early version of the manuscript. The manuscript will undergo copyediting, typesetting, and review of the resulting galley proof before it is published in its final citable form. Please note that during the production process errors may be discovered which could affect the content, and all legal disclaimers that apply to the journal pertain. 


\title{
ACCEPTED MANUSCRIPT
}

\section{Processing-property relationships of biaxially stretched poly(L-lactic acid)}

\section{sheet for application in coronary stents}

\author{
R. Blair ${ }^{a, *}$, N. Dunne ${ }^{b, c, d}, A$. Lennon $^{a}$, G. Menary ${ }^{a}$ \\ ${ }^{a}$ School of Mechanical and Aerospace Engineering, Queen's University, BT9 5AH, Belfast, UK \\ ${ }^{b}$ Centre for Medical Engineering Research, School of Mechanical and Manufacturing Engineering, \\ Dublin City University, Dublin 9, Ireland
}

'School of Pharmacy, Queen's University, Belfast, BT9 7BL, UK

${ }^{\mathrm{d}}$ Trinity Centre for Bioengineering, Trinity College Dublin, Dublin 2, Ireland

*Corresponding address: School of Mechanical and Aerospace Engineering, Queen's University, Ashby Building, Stranmillis Rd, Belfast BT9

5AG, UK. Tel.: +44 (0)289097 5523. E-mail address: rblair522@qub.ac.uk

\section{Abstract}

The development of coronary stents from poly(L-lactic acid) requires knowledge of its mechanical properties and the effects of manufacturing processes on those properties. The effects of the biaxial stretching procedure on the mechanical and microstructural properties of poly(L-lactic acid) are hereby investigated. The mechanical properties were evaluated before and after biaxial stretching, with a Design of Experiments methodology employed to identify processing parameters that had the most significant effect on the elastic modulus and yield strength of the biaxially stretched sheets. Microstructural characterisation was performed using differential scanning calorimetry to evaluate crystallinity and thermal transitions of the biaxially stretched sheets. The results show that the mechanical properties of the stretched sheets are highly dependent on the extent of stretch ratio applied during processing; however, neither the elastic modulus nor yield strength are directly attributable to crystallinity, but are affected by the degree of amorphous orientation. The results of this study have the potential to be applied in the design of high stiffness, thin-strut polymeric expandable scaffolds for the application of coronary stents. 


\section{ACCEPTED MANUSCRIPT}

\section{Introduction}

Coronary heart disease (CHD) is the largest cause of death in the world (Abubakar et al., 2015) and is commonly caused by atherosclerosis, an inflammatory disease that hardens and narrows the artery (Ludman et al., 2016). Coronary stents are small expandable scaffolds deployed at the site of an atherosclerotic lesion in order to dilate the artery and restore patency. Typically, coronary stents are manufactured from high strength metallic alloys such as stainless steel (316L) and cobaltchromium L605 (Grogan et al., 2012). However, these scaffolds remain in the body post-procedure and have the potential to trigger an undesirable immunological response (Bourantas et al., 2013). Bioresorbable polymer stents offer a potentially clinically attractive solution, providing a temporary scaffold that resorbs once the artery has healed.

Poly(L-lactic acid) (PLLA) is a biodegradable, aliphatic polyester manufactured from renewable resources (Drumright et al., 2000; Garlotta, 2001), which has been used as a platform material of a bioresorbable stent with the Absorb Bioresorbable Vascular Scaffold (BVS) (Abbott Vascular, USA), gaining U. S. Food and Drug Administration (FDA) approval in July, 2016 (U. S. Food and Drug Administration, 2016). Bioresorbable scaffolds offer a number of key advantages over their permanent metal counterparts, such as late lumen enlargement (after the scaffold resorbs) and fewer complications during repeat revascularisation procedures (Serruys et al., 2011). There are, however, a number of initial issues preventing the successful implementation of bioresorbable scaffolds within wider treatment scenarios such as late recoil, caused by the fast absorption of the scaffold, and difficulties in controlling the drug release (Bourantas et al., 2013). The primary disadvantage of using PLLA as the platform material for a bioresorbable coronary stent is that significantly thicker struts are required to provide the same level of arterial support when compared to a conventional metallic stent (Kawamoto et al., 2016; Kolandaivelu et al., 2011), primarily due to a comparatively lower modulus (Bergström and Hayman, 2015; Bobel et al., 2016). The results of clinical studies suggest that the increased strut profile of the BVS may increase the risk of myocardial 


\section{ACCEPTED MANUSCRIPT}

infarction and thrombosis (Serruys et al., 2016; U. S. Food and Drug Administration, 2017a) and, as a result, Abbott has recently stopped global sales of the device (U. S. Food and Drug Administration, 2017b). One potential method to reduce the strut thickness of PLLA stents is to improve the mechanical properties of the polymer through tailoring the processing history.

Stretch blow moulding (SBM) is a processing technique commonly employed in the commercial production of carbonated drinks bottles to improve their tensile modulus, strength-to-weight ratio, fracture strain and shelf-life (Brandau, 2016), and was adopted for use in the production of the BVS. In the SBM procedure for scaffolds, the polymer is initially melted and extruded to form a thick walled tube, commonly referred to as a parison (or preform). The parison is heated above its glass transition temperature $\left(T_{g}\right)$ and stretched at high speed circumferentially using pressurised air, and axially using a mechanical device such as an actuator. The process creates a thin-walled tube, typically 3 to 5 times the initial parison outer diameter, with improved mechanical properties (Alexy and Levi, 2013; Bergström and Hayman, 2015). The SBM process imposes a state of biaxial strain on the parison, and may be replicated using a biaxial tensile test machine that stretches polymer sheet in a planar configuration (Menary et al., 2012). In general, the biaxial deformation behaviour of semi-crystalline polymers exhibits a strong dependence on temperature, deformation mode, strain rate and stretch ratio during processing (Løvdal et al., 2017; Løvdal et al., 2015; Menary et al., 2012; Ou and Cakmak, 2008).

The temperature window for biaxial processing of PLLA is limited by its $T_{g}$ and cold-crystallisation temperature $\left(T_{c c}\right)$, both of which vary depending on its chemical composition and processing history (Ou and Cakmak, 2008). However, in general, the $T_{g}$ is within the range of $50-65^{\circ} \mathrm{C}$ (Bergström and Hayman, 2015; Løvdal et al., 2015; Ou and Cakmak, 2008; Wu et al., 2012), whilst the $T_{c c}$ is within the range $110-145{ }^{\circ} \mathrm{C}$ (Stoclet et al., 2010; Løvdal et al., 2017). This suggests that PLLA should be processed above the $\mathrm{T}_{\mathrm{g}}$ but below $85^{\circ} \mathrm{C}$ in order to supress cold crystallisation and facilitate strain- 


\section{ACCEPTED MANUSCRIPT}

induced crystallisation, which subsequently improves both the strength and stiffness of the polymeric sheet.

The deformation mode during biaxial stretching may be defined as simultaneous or sequential, the latter consisting of constant width drawing in two directions (Martin et al., 2005). The deformation mode has been shown to affect the structural evolution of the polymer (Løvdal et al., 2015; Ou and Cakmak, 2008; Ou and Cakmak, 2010). Løvdal et al. (2015) found that the sequence by which the strain occurs during biaxial processing influences crystal orientation and interplanar spacing, but not the degree of crystallinity $\left(X_{c}\right)$. Ou and Cakmak (2008) showed that simultaneous stretching leads to in-plane isotropy with relatively poorly ordered crystalline regions. In a stepwise sequential deformation process, the first (machine) direction stretch orients the polymer and increases crystallinity. However, stretching in the second (transverse) direction leads to the destruction of crystallites, particularly if the crystalline structure was well established during the first stretch.

The elastic modulus (E) and yield strength $(\sigma)$ of PLLA post biaxial deformation have been shown to be a function of both the strain rate and stretch ratio during biaxial processing (Løvdal et al., 2015; Wu et al., 2012). Low strain rates $\left(0.1 \mathrm{~s}^{-1}\right)$ permit chain relaxation during biaxial processing, which subsequently result in reduced mechanical properties of the stretched polymer. However, increased strain rate $\left(2.1 \mathrm{~s}^{-1}\right)$ has been shown to increase crystallinity and molecular orientation, and subsequently improve the mechanical properties of the stretched polymer (Løvdal et al., 2017). The slow crystallisation rate of PLLA is enhanced by deformation, which facilitates strain-induced molecular ordering (Stoclet et al., 2010; Tsai et al., 2010; Zhang et al., 2011), with Løvdal et al. (2015) hypothesising that the mechanical properties of PLLA are related to strain-induced amorphous orientation rather than strain-induced crystallinity.

Comprehensive mechanical characterisation has been performed for PLLA, using a polymer that is solvent cast (Bobel et al., 2016; Ouchi et al., 2006; Venkatraman et al., 2002) or injection moulded (Bigg, 1996; Ghosh et al., 2007; Harris and Lee, 2008). However, the processing history of PLLA 


\section{ACCEPTED MANUSCRIPT}

significantly affects the mechanical properties of the polymer, with biaxially stretched samples often demonstrating an increased elastic modulus, yield strength and elongation to failure, when compared to the unstretched polymer (Wu et al., 2012). The reviewed literature suggests that temperature, stretch ratio, strain rate, and deformation mode each affect biaxial deformation behaviour and the resultant mechanical properties of the stretched sheet. However, to the best of the authors' knowledge, the interdependencies between these aforementioned processing parameters and their effect on the elastic modulus and yield strength of the post biaxially stretched sheet have not been investigated for PLLA. The aim of the present study is to replicate the processing history of a polymeric coronary stent and evaluate the improvement in short-term (predegradation) mechanical properties of extruded PLLA post biaxial stretching, in order to facilitate the design of high stiffness, thin strut polymeric scaffolds for the application of coronary stents.

\section{Material and methods}

Pellets of PLLA (Tradename: Plurapol LX175) were donated by Corbion Purac (Amsterdam, The Netherlands). The pellets were dried for $12 \mathrm{~h}$ at $70{ }^{\circ} \mathrm{C}$ to remove the moisture prior to melt processing. Melt extrusion was performed using an E $25 \mathrm{M}$ Dr Collin single screw extruder (Dr. Collin $\mathrm{GmbH}$, Germany). During the extrusion process, the barrel temperature was set at $200{ }^{\circ} \mathrm{C}$ with a screw speed of $50 \mathrm{rpm}$ and a CR 136/350 chill roll stack (Dr. Collin GmbH, Germany) temperature of $50{ }^{\circ} \mathrm{C}$. Gel permeation chromatography (GPC) was performed on both pellets and extruded sheet in order to ensure that molecular weight did not significantly decrease during melt processing. An Agilent Technologies 1260 Infinity GPC system (Agilent Technologies, USA) with an eluent of tetrahydrofuran (THF) containing $2.0 \% \mathrm{v} / \mathrm{v}$ triethylamine and $0.05 \% \mathrm{w} / \mathrm{v}$ butylated hydroxytoluene (BHT) inhibitor was used. Post-processing of the results was performed using Cirrus GPC software (Agilent Technologies, USA). 


\section{ACCEPTED MANUSCRIPT}

Poly(L-lactic acid) samples, each with dimensions of $76 \mathrm{~mm} \times 76 \mathrm{~mm} \times 1 \mathrm{~mm}$ were prepared for biaxial stretching, which was performed using a custom-built machine (Martin et al., 2005) that was designed to replicate the deformation behaviour of polymeric materials during SBM under controllable conditions (i.e. deformation mode, deformation temperature, and deformation rate). The biaxial stretching machine is capable of supplying a maximum stretch speed of $2400 \mathrm{~mm} / \mathrm{s}$, equivalent to an average nominal strain rate $(\dot{\varepsilon})$ of $32 \mathrm{~s}^{-1}$, and a maximum stretch ratio $(\lambda)$ of 4.5 in both the machine direction (MD) and transverse direction (TD). A constant temperature (T) of up to $200{ }^{\circ} \mathrm{C}$ is attainable and the deformation mode may be varied from simultaneous (SIM) biaxial deformation to sequential (SEQ) biaxial deformation (Fig. 1) (Martin et al., 2005). Details of userdefined test conditions may be found in subsequent sections.

Uniaxial tensile testing was performed using an Instron 5564 Universal Material Testing machine (Instron, UK) to determine the elastic modulus and yield strength of both unstretched and biaxially stretched sheet. Uniaxial testing was conducted in accordance with the test protocol as outlined in ISO 527-2 Type 1BA (ISO, 1996). The samples $(n=3)$ tested were dumb-bell in shape; samples were punched from unstretched sheet in the extrusion direction (ED) and TD, whilst samples were punched from biaxially stretched sheet in MD and TD. All samples were tested at room temperature $\left(20^{\circ} \mathrm{C} \pm 3{ }^{\circ} \mathrm{C}\right)$ at an extension rate similar to that recommended for bioresorbable scaffold deployment (5 mm/min), according to published guidelines from Abbott (Abbott Vascular, 2012). 


\section{ACCEPTED MANUSCRIPT}

(a)

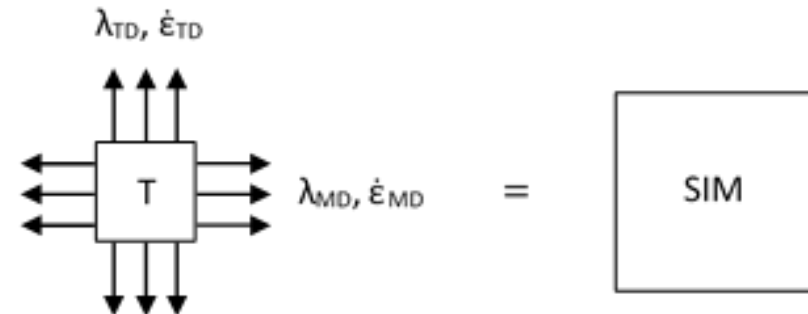

TD

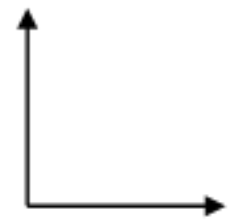

MD

(b)
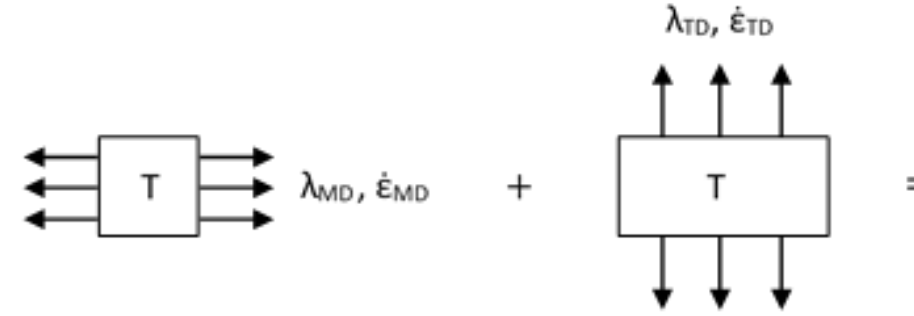

SEQ

Fig. 1. Biaxial deformation parameters used to replicate SBM processing history for (a) simultaneous (SIM) biaxial deformation and (b) sequential (SEQ) biaxial deformation.

A Design of Experiments (DOE) approach was employed to identify the biaxial stretching processing parameters that most significantly affect the elastic modulus and yield strength of the stretched sheet. A one-half fraction of a six factor, two-level factorial $\left(2^{6-1}\right)$ randomised design was used with the following factors: stretch ratio in $\mathrm{MD}\left(\lambda_{\mathrm{MD}}\right)$, stretch ratio in TD $\left(\lambda_{\mathrm{TD}}\right)$, deformation speed in $\mathrm{MD}$ $\left(\dot{\varepsilon}_{\mathrm{MD}}\right)$, deformation speed in TD $\left(\dot{\varepsilon}_{\mathrm{TD}}\right)$, temperature, and deformation mode. A $2^{6-1}$ fractional factorial is an example of a resolution VI design and, hence, main factors are aliased with five-way interactions (and above), whilst two-way interactions are aliased with three-way interactions (and above). Design of Experiments screening permits the significant factors to be isolated from those that have minimal effect on the response variable(s). Preliminary testing was performed to identify upper and lower limits for the processing parameters evaluated under the DOE (Table 1). Samples were heated for $3 \mathrm{~min}$ prior to biaxial stretching in order to achieve uniform temperature distribution through the thickness. The temperature was held within the range $80-90^{\circ} \mathrm{C}$; below 80 ${ }^{\circ} \mathrm{C}$ the polymer behaved as a glassy solid whilst above $90{ }^{\circ} \mathrm{C}$ the polymer began to undergo coldcrystallisation. The strain rate was held within the range $1-16 \mathrm{~s}^{-1}$, with faster rates leading to grip slippage during stretching. The maximum total area of deformation $\left(A_{\text {def }}\right)$, defined as the product 


\section{ACCEPTED MANUSCRIPT}

of the stretch ratios in MD and TD, which could be consistently achieved was 9, which was attainable through a $3 \times 3$ equibiaxial deformation-hence, the stretch ratio was held within the range 2-3. Response surface methodology (RSM) was employed to refine the design space of the significant factors, with multiple regression analysis performed on the results using $\mathrm{R}$ (version 3.4.0) ( $\mathrm{R}$ Core Team, 2017) in order to provide an empirical correlation between biaxial stretching processing parameters and the mechanical properties of the stretched sheet.

Table 1. High and low levels for stretch ratio in $\operatorname{MD}\left(\lambda_{\mathrm{MD}}\right)$, stretch ratio in $\operatorname{TD}\left(\lambda_{\mathrm{TD}}\right)$, deformation speed in $\mathrm{MD}\left(\dot{\varepsilon}_{\mathrm{MD}}\right)$, deformation speed in TD $\left(\dot{\varepsilon}_{\mathrm{TD}}\right)$, temperature $(\mathrm{T})$ and deformation mode evaluated under the DOE.

\begin{tabular}{|c|c|c|c|c|c|}
\hline$T$ & $\dot{\varepsilon}_{M D}$ & $\dot{\varepsilon}_{T D}$ & $\lambda_{M D}$ & $\lambda_{T D}$ & Mode \\
\hline$\left({ }^{\circ} \mathrm{C}\right)$ & & & & $(-)$ & \\
\hline 80 & 1 & 1 & 2 & 2 & SEQ \\
\hline 90 & 16 & 16 & 3 & 3 & SIM \\
\hline
\end{tabular}

Differential scanning calorimetry (DSC) was conducted on both unstretched and biaxially stretched sheet to evaluate both the crystallinity and the thermal characteristics of the polymer. Test samples $(n=3)$ were taken from randomly selected sections over the PLLA sheet, weighing approximately 8 $\mathrm{mg}$, and placed individually into an aluminium pan, sealed and subjected to a heating cycle of $10{ }^{\circ} \mathrm{C} / \mathrm{min}$ between the limits of $30^{\circ} \mathrm{C}$ and $180^{\circ} \mathrm{C}$, using a PerkinElmer DSC6 (PerkinElmer, USA). Post-processing of the results was performed using Pyris ${ }^{\mathrm{TM}}$ software (Version 9.0, Perkin-Elmer, USA) to identify crystallinity $\left(X_{c}\right), T_{g}, T_{c c}$ and the melting temperature $\left(T_{m}\right)$ of the polymer. The crystallinity was calculated using Eq. 1 (Løvdal, 2017), taking the enthalpy of fusion, $\Delta \mathrm{H}^{\circ}$, as $93 \mathrm{~J} / \mathrm{g}$ based on the value for a $100 \%$ crystalline sample (Wunderlich, 1990).

$$
X_{c}(\%)=\frac{\left(\Delta \mathrm{H}_{m}-\Delta \mathrm{H}_{c}\right)}{\Delta H^{0}} \times 100 \%
$$




\section{Results}

\subsection{Unstretched sheet}

The mechanical and thermal properties for unstretched PLLA (Table 2) demonstrated that the polymer is relatively amorphous (approximately 4\% crystallinity). A two-sample t-test showed no significant statistical difference $(p>0.05)$ between the moduli in the extrusion direction (ED) and TD. Whilst yield strength showed a $14 \%$ difference between ED and TD, the polymer was assumed to have limited preferential orientation post-extrusion. The results of GPC indicated that there was no significant reduction in molecular weight during melt processing, with both the pellets and extruded sheet having a weight-average molecular weight and polydispersity index of $230 \mathrm{~kg} \mathrm{~mol}^{-1}$ and 2.0, respectively. The properties outlined in Table 2 were used as comparative measures to evaluate the effect of the biaxial stretching process on the mechanical and thermal properties of the polymer at a macro- and microstructural level.

Table 2. Elastic modulus (E) and yield strength $(\sigma)$ for samples taken from the extrusion direction (ED) and transverse direction (TD), crystallinity $\left(X_{c}\right)$ and thermal transitions $\left(T_{g}, T_{c c}, T_{m}\right)$ for unstretched PLLA sheet.

\begin{tabular}{cccccccc}
\hline$E_{E D}$ & $E_{T D}$ & $\sigma_{M D}$ & $\sigma_{T D}$ & $X_{c}$ & $T_{g}$ & $T_{c c}$ & $T_{m}$ \\
\hline & $(\mathrm{MPa})$ & & & $(\%)$ & & $\left.{ }^{\circ} \mathrm{C}\right)$ & \\
\hline $2315 \pm 137$ & $2181 \pm 129$ & $55 \pm 1$ & $48 \pm 2$ & $4 \pm 1$ & $62 \pm 0.8$ & $120 \pm 0.3$ & $149 \pm 0.1$ \\
\hline
\end{tabular}

\subsection{Stretched sheet}

The main effect plots from the DOE (Fig. 2(a) and Fig. 2(b)) describe the effect of each factor on the elastic modulus and yield strength, independent from all other factors. The steeper the slope of the line, the greater the magnitude of that main factor's effect; the dotted line for each response 


\section{ACCEPTED MANUSCRIPT}

variable represents the mean value across all runs. The elastic modulus and yield strength of the stretched sheet are, in general, most significantly affected by stretch ratio, with strain rate, temperature, and deformation mode each having a relatively lesser effect. The absolute effects of all main factors and two-way interactions on the elastic modulus and yield strength are annotated on half-normal probability plots (Fig. $3(a)-3(d))$, with effects that are statistically significant $(p<$ 0.05) highlighted on each graph. The effects of statistically insignificant factors (and interactions) describe a straight line on the plots, whilst the effects of statistically significant factors (and interactions) are displaced from this line. The further the distance a factor or interaction is from the line, the more significant its effect. In general, two-way interactions are statistically insignificant, with stretch ratio in both MD and TD having the most dominant effect. An increased elastic modulus and yield strength in a given direction was obtained by increasing the stretch ratio in that direction, with a further increase attainable if the stretch ratio in TD was reduced. Setting all factors to their optimum level increased the $\mathrm{E}_{\mathrm{MD}}$ and $\mathrm{E}_{\mathrm{TD}}$ by $49 \%$ and $62 \%$, respectively when compared to all factors set at their pessimal level, and the $\sigma_{\mathrm{MD}}$ and $\sigma_{\mathrm{TD}}$ increased by $47 \%$ and $52 \%$, respectively.

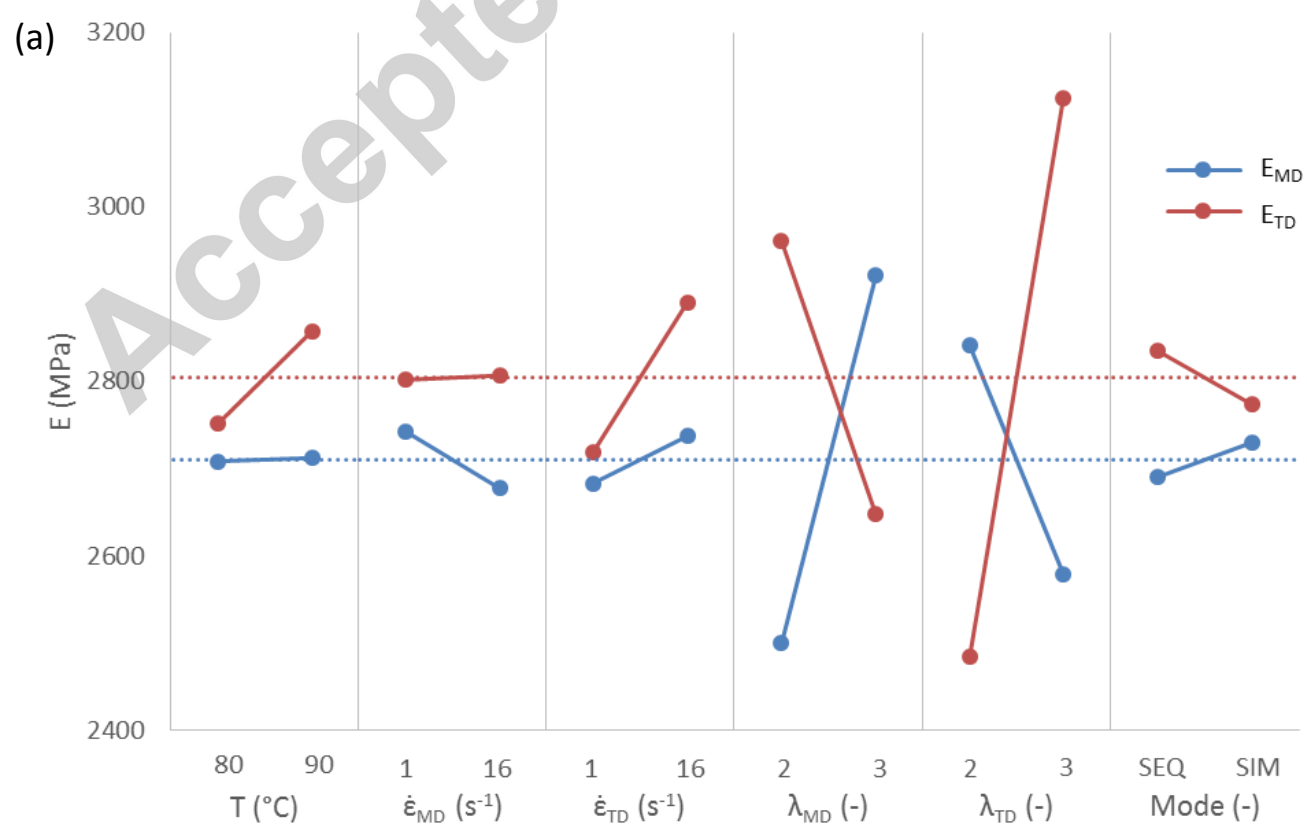




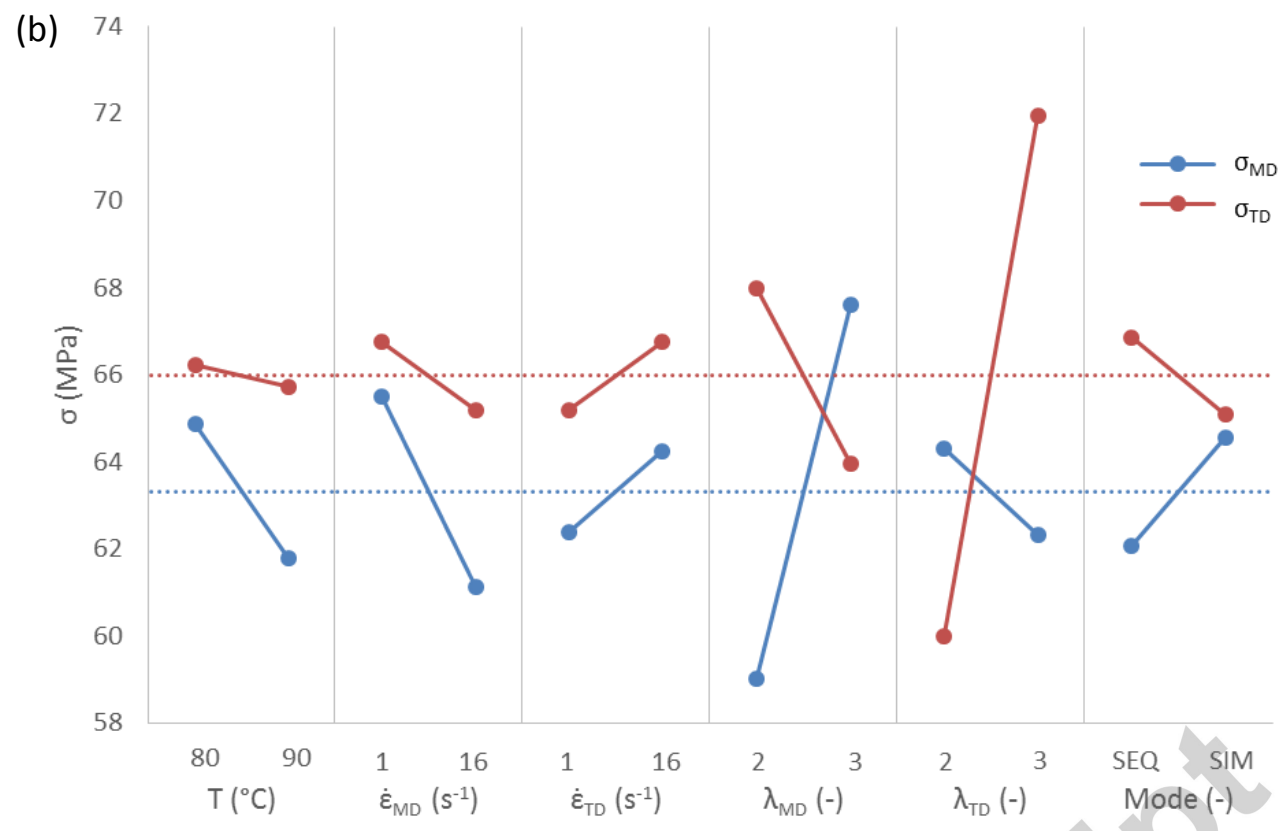

Fig. 2. Main effect plots highlighting the dominance of stretch ratio in the machine direction (MD) and transverse direction (TD) for (a) Elastic modulus (E) of PLLA sampled from MD and TD, $E_{M D}$ and $E_{T D}$, respectively; and (b) Yield strength $(\sigma)$ in $M D$ and TD, $\sigma_{M D}$ and $\sigma_{T D}$, respectively.

(a) $E_{M D}(\mathrm{MPa})$

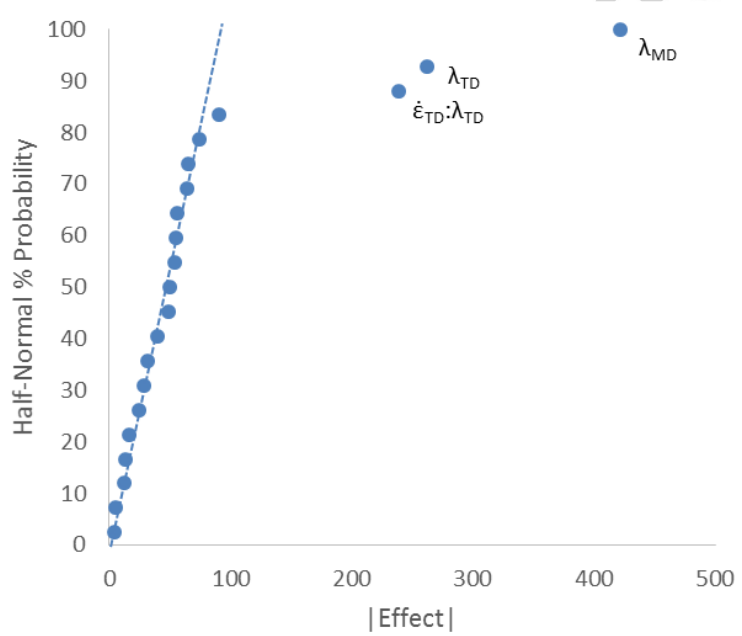

(c) $\sigma_{\mathrm{MD}}(\mathrm{MPa})$ (b) $\mathrm{E}_{\mathrm{TD}}(\mathrm{MPa})$

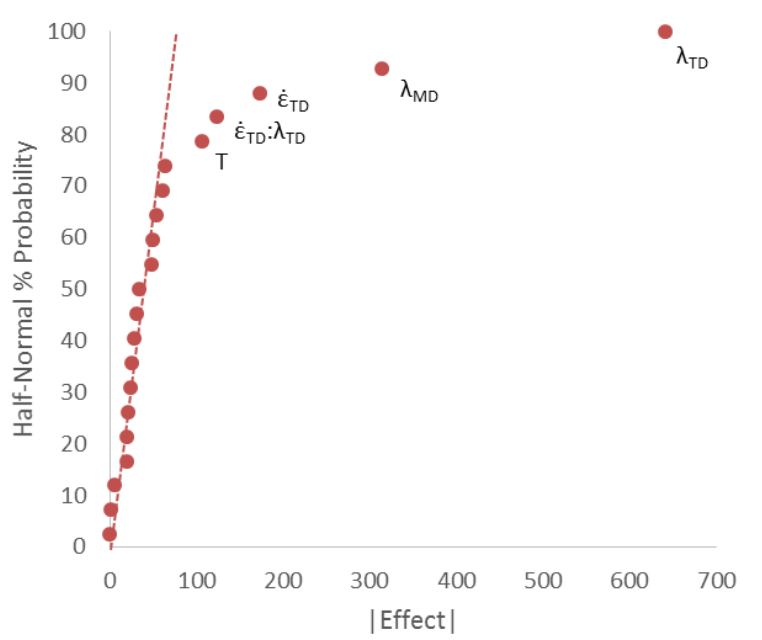

(d) $\sigma_{\mathrm{TD}}(\mathrm{MPa})$ 

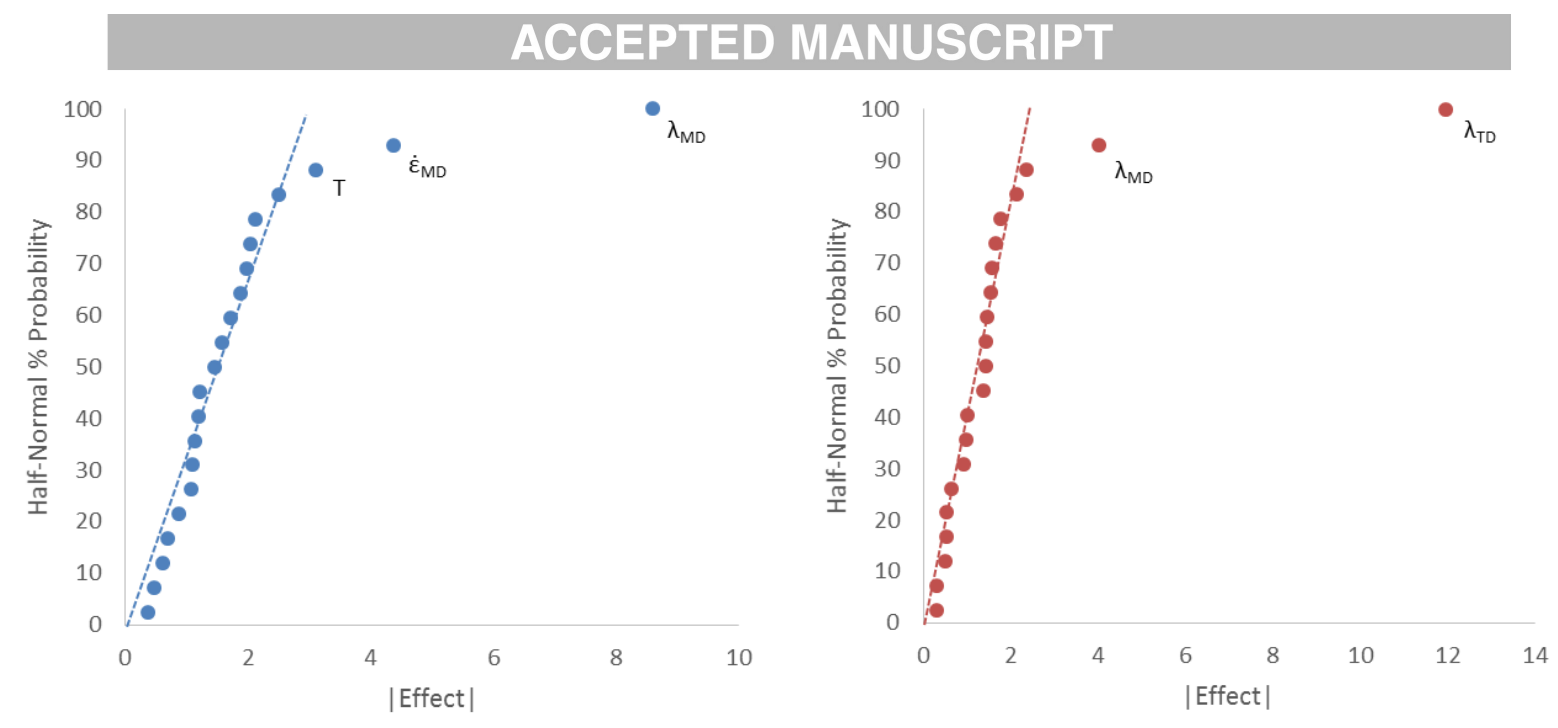

Fig. 3. Half-normal probability plots for main factors and two-way interactions highlighting the dominance of stretch ratio in the machine direction (MD) and transverse direction (TD) for (a) Elastic modulus (E) in MD, $E_{M D}$; (b) Elastic modulus (E) in TD, $E_{T D}$; (c) Yield strength ( $\sigma$ ) in $M D, \sigma_{M D}$ and (d) Yield strength $(\sigma)$ in TD, $\sigma_{\mathrm{TD}}$.

Although the $2^{6-1}$ fractional factorial design matrix permitted the evaluation of asymmetrical biaxial deformations such as $2 \times 3$ and $3 \times 2$, it was incapable of capturing the response of highly asymmetrical deformations, approaching that of a constant width deformation (where one axis is fully constrained). Response surface methodology was employed to refine the design space and provide an empirical correlation between stretch ratio and the mechanical properties of the polymer. The range of stretch ratios evaluated was modified from the DOE to include a low level of 1.5 and a high level of 3.5. Temperature was held constant at $80^{\circ} \mathrm{C}$, stretch speed in MD and TD was also held constant at $16 \mathrm{~s}^{-1}$ and a sequential deformation mode was used, with the aforementioned conditions providing the most repeatable deformation during biaxial tensile testing.

Multiple regression analysis of the RSM results (Table 3) was performed to generate 2D contour plots that relate both elastic modulus and yield strength to the stretch ratio (Fig. $4(a)-4(d)$ ). The stepwise routine identifies a model containing the intercept, main factors, interaction and both squared terms. Empirical relations were generated from the regression analysis for both modulus 


\section{ACCEPTED MANUSCRIPT}

and yield strength, including effects that were statistically significant $(p<0.05)$ with Eq. $2-5$ achieving adjusted $R$-squared $\left(R_{\text {adj }}^{2}\right)$ values of $0.97,0.93,0.98$ and 0.87 , respectively.

Table 3. Elastic modulus (E) and yield strength $(\sigma)$ of specimens selected for response surface methodology (RSM) sampled from the machine direction (MD) and transverse direction (TD).

\begin{tabular}{cccccc}
\hline$\lambda_{M D}$ & $\lambda_{T D}$ & $E_{M D}$ & $\sigma_{M D}$ & $E_{T D}$ & $\sigma_{T D}$ \\
\hline \multicolumn{5}{c}{$(-)$} & \multicolumn{5}{c}{ (MPa) } \\
\hline 2 & 2 & $2456 \pm 122$ & $61 \pm 4$ & $2499 \pm 41$ & $61 \pm 1$ \\
3 & 2 & $3274 \pm 51$ & $74 \pm 2$ & $2083 \pm 83$ & $53 \pm 1$ \\
2 & 3 & $2236 \pm 194$ & $57 \pm 4$ & $3291 \pm 185$ & $73 \pm 4$ \\
3 & 3 & $2774 \pm 181$ & $66 \pm 4$ & $2583 \pm 114$ & $62 \pm 1$ \\
1.5 & 2.5 & $2244 \pm 35$ & $56 \pm 3$ & $3387 \pm 141$ & $74 \pm 1$ \\
3.5 & 2.5 & $3162 \pm 158$ & $73 \pm 3$ & $2535 \pm 241$ & $64 \pm 5$ \\
2.5 & 1.5 & $3274 \pm 135$ & $72 \pm 4$ & $2240 \pm 14$ & $59 \pm 1$ \\
2.5 & 3.5 & $2304 \pm 144$ & $57 \pm 2$ & $3011 \pm 97$ & $73 \pm 2$ \\
1.5 & 3.5 & $1898 \pm 99$ & $52 \pm 1$ & $4093 \pm 159$ & $84 \pm 1$ \\
3.5 & 1.5 & $3860 \pm 242$ & $83 \pm 2$ & $1987 \pm 155$ & $50 \pm 1$ \\
3.5 & 3.5 & $2632 \pm 109$ & $64 \pm 2$ & $2649 \pm 90$ & $66 \pm 2$ \\
2.5 & 2.5 & $2572 \pm 123$ & $62 \pm 2$ & $2369 \pm 161$ & $62 \pm 2$ \\
\hline
\end{tabular}

$E_{M D}=1305+998 \lambda_{M D}+20 \lambda_{T D}-184 \lambda_{M D} \lambda_{T D}$

$E_{T D}=5499-2704 \lambda_{M D}+444 \lambda_{T D}+428 \lambda_{M D}^{2}$

$\sigma_{M D}=36.8+17.4 \lambda_{M D}+1.6 \lambda_{T D}-3.2 \lambda_{M D} \lambda_{T D}$

$$
\sigma_{T D}=61.9-7.4 \lambda_{M D}+8.6 \lambda_{T D}
$$




\section{ACCEPTED MANUSCRIPT}

The thermal and microstructural properties of the RSM specimens are of particular interest when plotted against the total area of deformation, calculated as the product of the stretch in MD and the stretch in TD (Fig. 5(a)-5(d)). Results show that there was no statistical correlation between either crystallinity or $T_{m}$ and total area of deformation, with $R^{2}$ values of 0.06 and 0.03 , respectively. The $T_{g}$ and $T_{c c}$ both show correlation with total area of deformation, with $R^{2}$ values of 0.53 and 0.71 , respectively.

(a) $E_{M D}(M P a)$

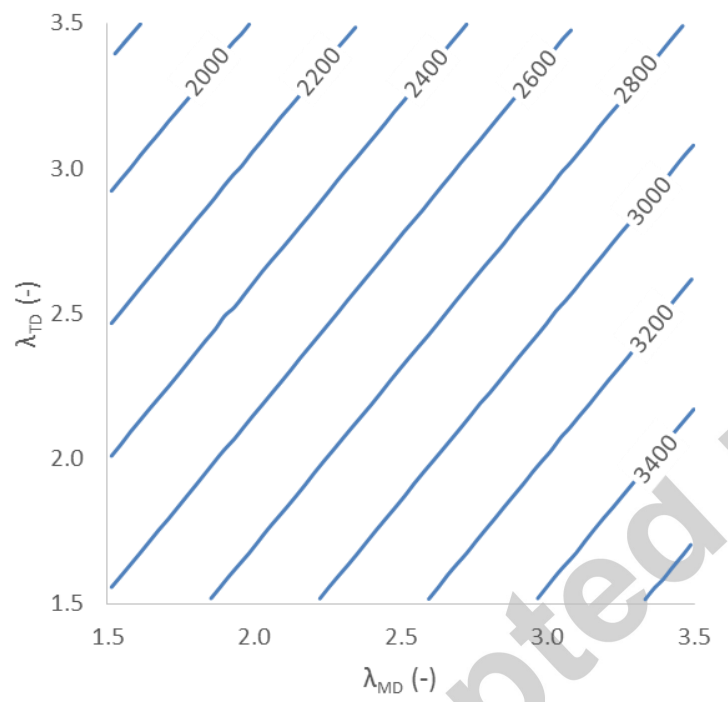

(c) $\sigma_{\mathrm{MD}}(\mathrm{MPa})$ (b) $\mathrm{E}_{\mathrm{TD}}(\mathrm{MPa})$

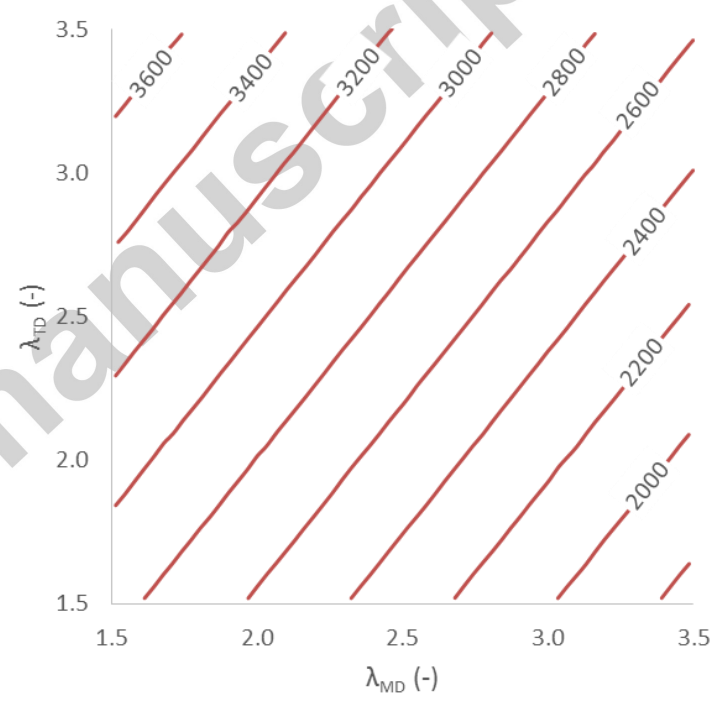

(d) $\sigma_{\mathrm{TD}}(\mathrm{MPa})$ 

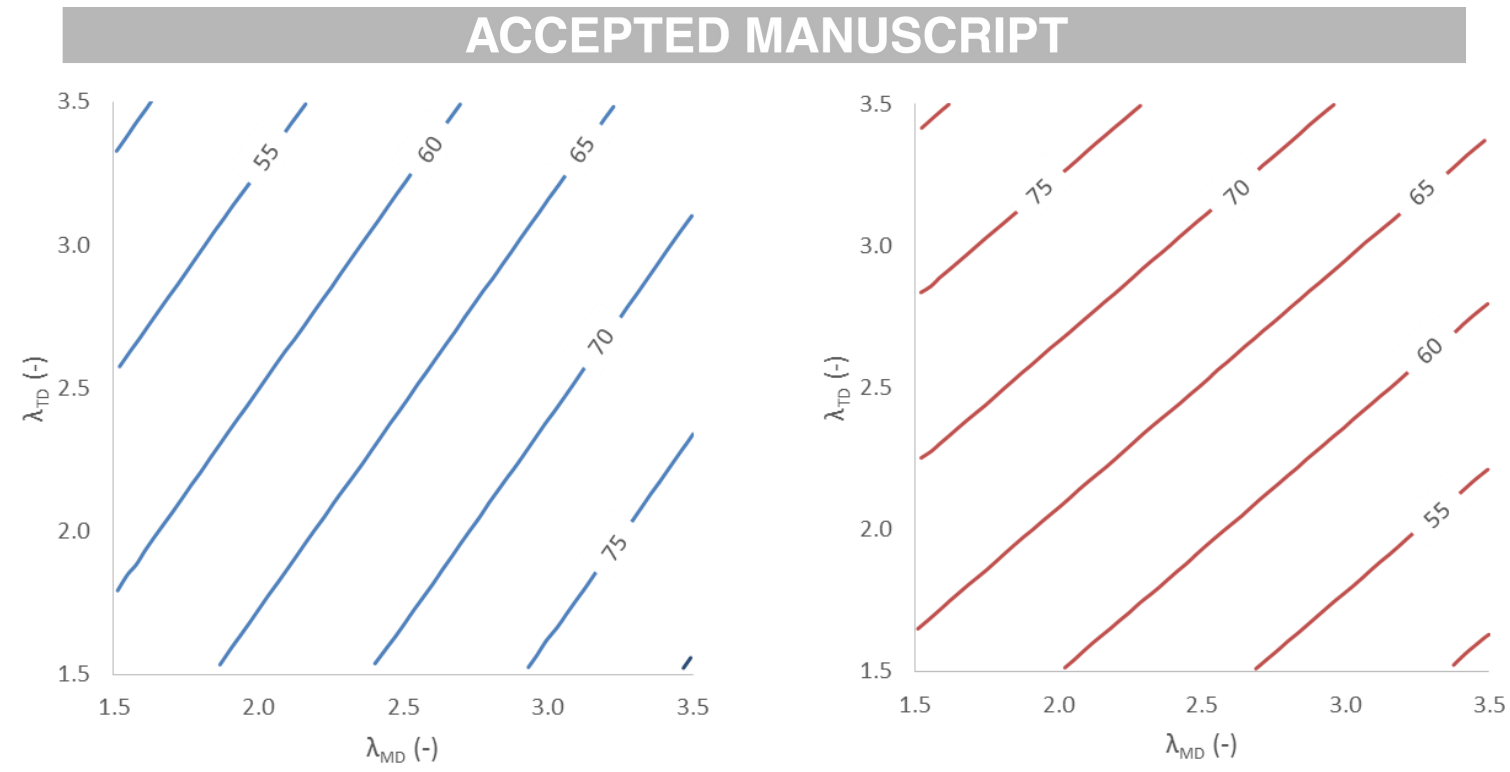

Fig. 4. Isoline contour plots for (a) Elastic modulus (E) in the machine direction (MD), $E_{M D}$; (b) Elastic modulus (E) in the transverse direction (TD), $\mathrm{E}_{\mathrm{TD}}$; (c) Yield strength $(\sigma)$ in $\mathrm{MD}, \sigma_{\mathrm{MD}}$; and (d) Yield strength $(\sigma)$ in TD, $\sigma_{\mathrm{TD}}$.
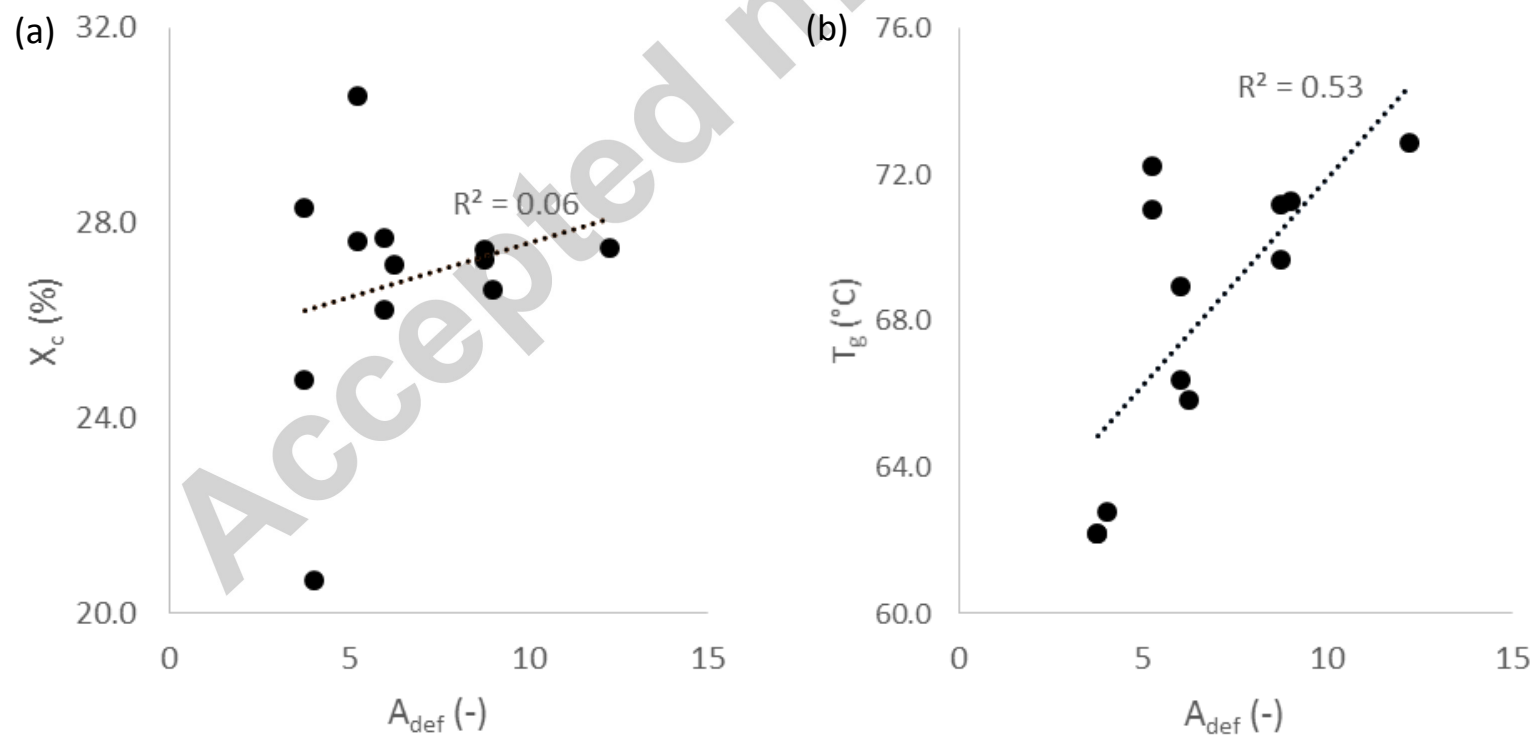

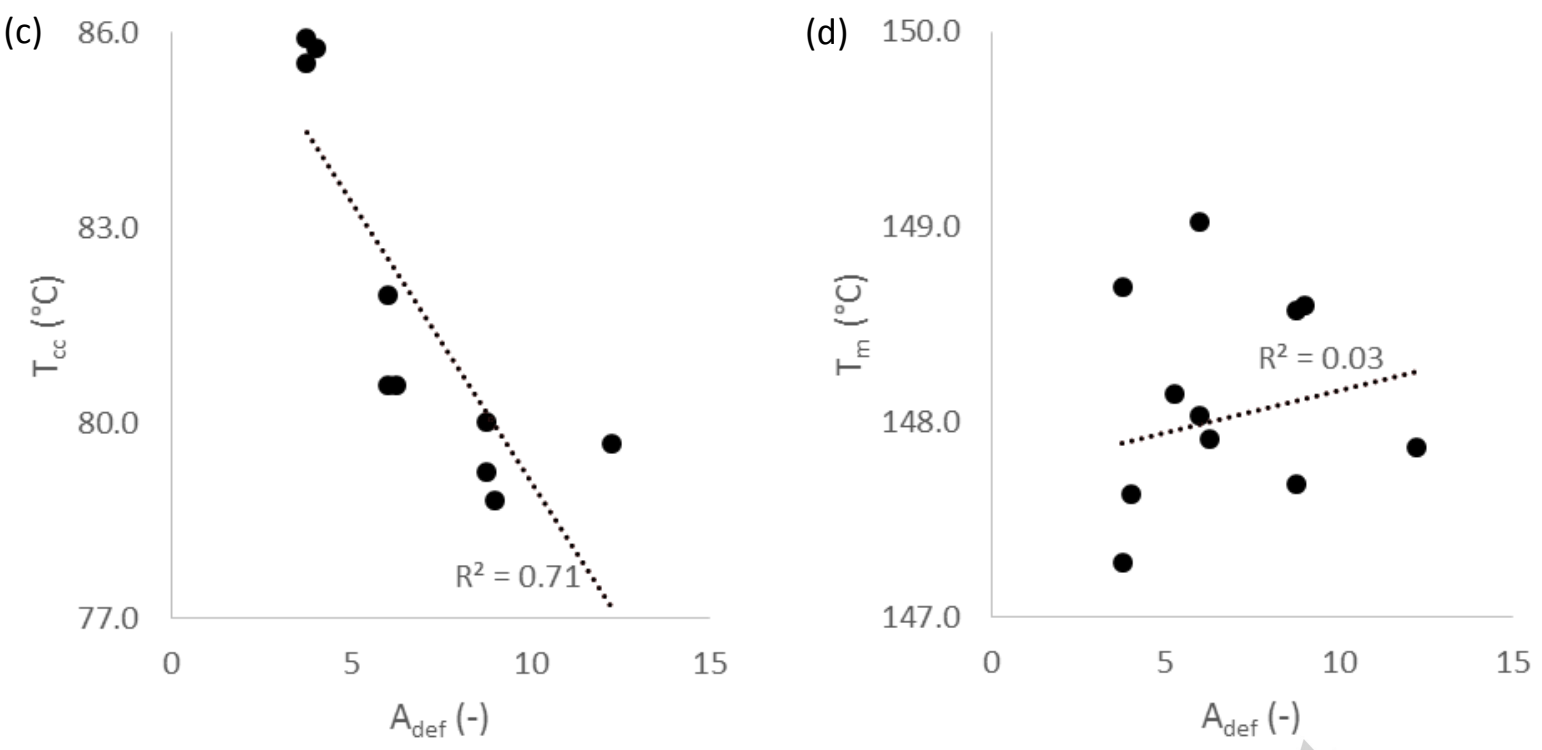

Fig. 5. Total area of deformation $\left(\mathbf{A}_{\text {def }}\right)$ plotted against (a) Crystallinity, $X_{c}$; (b) Glass transition temperature, $T_{g}$; (c) Cold-crystallisation temperature, $T_{c c}$; and (d) Melting temperature, $T_{m}$ for response surface methodology (RSM) specimens.

\section{Discussion}

In this study, the processing history of a polymeric coronary stent was replicated using a custombuilt biaxial tensile test machine, in order to evaluate the improvement in short-term (predegradation) mechanical properties of extruded PLLA post biaxial stretching. Given that the elastic modulus of the platform material is considered to be the most important parameter in bioresorbable scaffold design (Bobel et al., 2015; Pauck and Reddy, 2015), optimising processing conditions has the potential to facilitate the design of high stiffness, thin-strut polymeric scaffolds for the application of coronary stents.

Results of this study show that biaxial deformation has the potential to enhance the elastic modulus and yield strength of extruded PLLA sheet by approximately $80 \%$ and $70 \%$, respectively, with the aforementioned mechanical properties most significantly affected by stretch ratio during processing. 


\section{ACCEPTED MANUSCRIPT}

An increased elastic modulus and yield strength in a given direction were obtained through increasing the stretch ratio, with a further increase attainable if the stretch ratio in TD was reduced. Conversely, equibiaxially deformed sheets exhibited in-plane isotropy suggesting that the orientation developed during the first stretch was destroyed as a result of the second transverse stretch, supporting the hypothesis of Ou and Cakmak (2008). Intuitively, this is to be expected, as a highly asymmetrical biaxial deformation tending towards constant width deformation has been shown to enhance the mechanical properties in the direction of stretching for other semi-crystalline polymers (Marco et al., 2002). Strain rate, temperature, and deformation mode each had a lesser effect on the mechanical properties of the stretched sheet, when compared to that of stretch ratio. The deformation mode (SIM or SEQ) did not significantly affect the elastic modulus or yield strength in either MD or TD, suggesting that whilst the sequence in which the strain occurs during biaxial processing influenced crystal orientation (Løvdal et al., 2015; Ou and Cakmak, 2008), it has a limited effect on the resulting mechanical properties of the stretched PLLA sheet.

The results of DSC analysis showed there is no statistically significant relationship between crystallinity and total area of deformation, suggesting that molecular orientation may be more important than crystallinity to enhance elastic modulus and yield strength of biaxially stretched sheets. There exists an inverse relationship between $\mathrm{T}_{c c}$ and the degree of amorphous orientation in semi-crystalline polymers (Gowd et al., 2004; Vasanthan et al., 2013). Results of this study showed that a similar relationship exists between $\mathrm{T}_{c c}$ and total area of deformation. Furthermore, results showed an increase in glass transition temperature with total area of deformation, which may be due to limited chain motion as a result of increased molecular orientation (Tsai et al., 2010). Such findings support the hypothesis of Løvdal et al. (2015), who suggested that mechanical properties of PLLA are related to strain-induced amorphous orientation rather than strain-induced crystallinity. Within the present study, a significantly lower value of crystallinity was recorded for specimens subjected to an equibiaxial stretch ratio of 2 . Wu et al. (2012) observed a similar trend, suggesting that this may potentially be the critical level of elongation beyond which strain-induced 
crystallisation occurs. Such a hypothesis has already been proven for poly(ethylene terephthalate), with Marco et al. (2002) noting that crystallinity was increased beyond a stretch ratio of 2.

The empirical relations (Eq. 2-5) and contour plots (Fig. 4(a)-4(d)) relate the mechanical properties of the stretched sheets to the stretch ratio during biaxial processing, with the intention that they may be used to aid in the design and process optimisation of coronary stents. However, defining a set of stretch ratios to provide optimum mechanical properties in both MD and TD is not possible, given that both factors directly counteract each other; increasing stretch ratio in MD will increase the elastic modulus in MD, however will reduce the elastic modulus in TD. The optimal solution will primarily be governed by the loading requirements experienced by a vascular scaffold in vivo. One concern for polymeric scaffolds is that they do not possess the same degree of radial stiffness as that of a metallic scaffold. A scaffold must possess significant radial stiffness to provide support to the displaced arterial wall, which would suggest that it may be beneficial to process the polymer such that it has a preferential circumferential orientation. Furthermore, increasing circumferential modulus (to increase radial stiffness of the stent) should result in reduced axial modulus (and thus flexural stiffness of the stent), enabling the design of flexible stents (for tortuous arterial morphologies) that possess sufficient radial stiffness. Correct matching of material processing to scaffold design, through the use of the empirical relations presented herein, may aid in the design of high stiffness, thin-strut polymeric scaffolds that contend with the performance of a conventional metallic stent, suggesting an area for future investigation.

Although the processing-property relationships presented in this work provide an understanding of the effect of processing parameters on the mechanical response of PLLA, there are limitations associated with the present study. The modulus and yield strength of the post biaxially stretched sheets were measured at room temperature $\left(20^{\circ} \mathrm{C}\right)$, at an extension rate of $5 \mathrm{~mm} / \mathrm{min}$. Literature has shown the mechanical response of PLLA to be dependent on both strain-rate and temperature 


\section{ACCEPTED MANUSCRIPT}

(Løvdal et al. 2015). The testing framework presented herein may be adapted to include these additional response variables if required. In addition, elongation to failure was not considered as a performance metric during uniaxial tensile testing. In reality, elongation to failure must be considered when designing a stent, given that strains of up to $50 \%$ may be experienced during deployment (Bobel et al., 2016). However, elongation to failure is heavily dependent on both extension rate and temperature for polymers (Arruda et al., 1995), and correct matching of deployment parameters to material processing must be investigated in order to facilitate the design of high stiffness, thin strut, polymeric stents, suggesting an area for future work.

\section{Conclusion}

The processing history of a polymeric coronary stent was replicated using a custom-built biaxial tensile test machine in order to assess the improvement in short-term (pre-degradation) mechanical properties of extruded PLLA. Results indicated that biaxial deformation has the potential to enhance the elastic modulus and yield strength of extruded PLLA sheet by approximately $80 \%$ and $70 \%$, through selection of optimal processing conditions. The elastic modulus and yield strength of the biaxially stretched sheets were highly dependent on the stretch ratio during processing, with temperature, strain rate and deformation mode each having a comparatively less significant influence on these mechanical properties. The highest values of elastic modulus and yield strength were obtained through highly asymmetrical biaxial deformation, tending towards pure constant width. The results of DSC suggest that this increase in mechanical properties is not directly attributable to crystallinity content, but instead due to amorphous orientation (based on the inverse relationship observed between the $T_{c c}$ and the total area of deformation of biaxially stretched sheet). Constitutive equations that relate the elastic modulus and yield strength of biaxially stretched sheet to the stretch ratio during processing have been proposed, with the intention that they may potentially be used to aid in the design of high stiffness, thin-strut polymeric scaffolds. 


\section{ACCEPTED MANUSCRIPT}

\section{Acknowledgements}

The authors wish to acknowledge funding from the Engineering and Physical Sciences Research Council (EPSRC) and the Marie Skłodowska-Curie Research and Innovation Staff Exchange (RISE), grant agreement 691238. The authors also wish to acknowledge the research institutions involved in the Bi-Stretch-4-Biomed collaborative research project (California Institute of Technology, University of Warwick and ENEA: Italian National Agency for New Technologies, Energy and Sustainable Economic Development). Gel permeation chromatography was performed under the supervision of Dr Efrosyni Themistou in the School of Chemistry and Chemical Engineering at Queen's University Belfast (QUB). Uniaxial tensile testing and DSC testing were performed under the supervision of Dr Bronagh Millar and Dr Paula Douglas through the Polymer Processing Research Centre at QUB.

\section{References}

Abubakar, I. I., Tillmann, T., and Banerjee, A., 2015. Global, regional, and national age-sex specific all-cause and cause-specific mortality for 240 causes of death, 1990-2013: a systematic analysis for the Global Burden of Disease Study 2013. The Lancet, 385(9963):117-171.

Agrawal, C. M., Haas, K. F., Leopold, D. A., and Clark, H. G., 1992. Evaluation of poly (L-lactic acid) as a material for intravascular polymeric stents. Biomaterials, 13(3):176-182.

Arruda, E. M., Boyce, M. C., and Jayachandran, R., 1995. Effects of strain rate, temperature and thermomechanical coupling on the finite strain deformation of glassy polymers. Mechanics of Materials, 19(2-3):193-212.

Bergström, J. S. and Hayman, D., 2015. An overview of mechanical properties and material modeling of polylactide (PLA) for medical applications. Annals of Biomedical Engineering, 44(2):330340. 


\section{ACCEPTED MANUSCRIPT}

Bigg, D. M., 1996. Effect of copolymer ratio on the crystallinity and properties of polylactic acid copolymers. Proceedings of the 54th Annual Technical Conference of the Society of Plastics Engineers, 54(2):2028-2039.

Bobel, A. C., Lohfeld, S., Shirazi, R. N., and McHugh, P. E., 2016. Experimental mechanical testing of Poly (I-Lactide) (PLLA) to facilitate pre-degradation characteristics for application in cardiovascular stenting. Polymer Testing, 54:150-158.

Bourantas, C. V., Onuma, Y., Farooq, V., Zhang, Y., Garcia-Garcia, H. M., and Serruys, P. W., 2013. Bioresorbable Scaffolds: Current Knowledge, Potentialities and Limitations Experienced During their First Clinical Applications. International Journal of Cardiology, 167(1):11-21.

Brandau, O., 2016. Stretch Blow Molding. William Andrew, 3rd edition.

Drumright, R. E., Gruber, P. R., and Henton, D. E., 2000. Polylactic acid technology. Advanced Materials, 12(23):1841-1846.

ISO Standard 527-2, 1996. Plastics: Determination of Tensile Properties. Part 2: Test Conditions for Moulding and Extrusion Plastics.

Garlotta, D., 2001. A literature review of poly (lactic acid). Journal of Polymers and the Environment, 9(2):63-84.

Ghosh, S., Viana, J. C., Reis, R. L., and Mano, J. F., 2007. Effect of processing conditions on morphology and mechanical properties of injection-molded poly (I-lactic acid). Polymer Engineering \& Science, 47(7):1141-1147.

Gowd, E. B., Ramesh, C., Byrne, M. S., Murthy, N. S., and Radhakrishnan, J., 2004. Effect of molecular orientation on the crystallization and melting behavior in poly (ethylene terephthalate). Polymer, 45(19):6707-6712.

Grogan, J. A., Leen, S. B. and McHugh, P. E., 2012. Comparing Coronary Stent Material Performance on a Common Geometric Platform through Simulated Bench Testing. Journal of the Mechanical Behavior of Biomedical Materials, 12:129-138.

Harris, A. M. and Lee, E. C., 2008. Improving mechanical performance of injection molded PLA by controlling crystallinity. Journal of Applied Polymer Science, 107(4):2246-2255.

Kawamoto, H., Jabbour, R. J., Tanaka, A., Latib, A., and Colombo, A., 2016. The Bioresorbable Scaffold. JACC: Cardiovascular Interventions, 9(3):299-300. 


\section{ACCEPTED MANUSCRIPT}

Kolandaivelu, K., Swaminathan, R., Gibson, W. J., Kolachalama, V. B., Nguyen-Ehrenreich, K. L., Giddings, V. L., and Edelman, E. R., 2011. Stent Thrombogenicity Early in High-Risk Interventional Settings Is Driven by Stent Design and Deployment and Protected by Polymer-Drug Coatings Clinical Perspective. Circulation, 123(13):1400-1409.

Løvdal, A. L. V., Andreasen, J. W., Mikkelsen, L. P., Agersted, K., and Almdal, K., 2017. Mechanical properties of biaxially strained poly (I-lactide) tubes: Strain rate and temperature dependence. Journal of Applied Polymer Science, 134(33).

Løvdal, A., Andreasen, J. W., Mikkelsen, L. P., Agersted, K., and Almdal, K., 2015. Characterization of biaxial strain of poly (I-lactide) tubes. Polymer International, 65(1):133-141.

Ludman, P. et al., 2017. National Audit of Percutaneous Coronary Interventions Annual Public Report, Jan 2015 to Dec 2015. British Cardiovascular Intervention Society.

Martin, P. J., Tan, C. W., Tshai, K. Y., McCool, R., Menary, G., Armstrong, C. G., and Harkin-Jones, E. M. A., 2005. Biaxial characterisation of materials for thermoforming and blow moulding. Plastics, Rubber and Composites, 34(5-6):276-282.

Menary, G. H., Tan, C. W., Harkin-Jones, E. M. A., Armstrong, C. G., and Martin, P. J., 2012. Biaxial deformation and experimental study of PET at conditions applicable to stretch blow molding. Polymer Engineering \& Science, 52(3):671-688.

Meng, B., Wang, J., Zhu, N., Meng, Q. Y., Cui, F. Z., and Xu, Y. X., 2006. Study of biodegradable and self-expandable PLLA helical biliary stent in vivo and in vitro. Journal of Materials Science: Materials in Medicine, 17(7):611-617.

Ou, X. and Cakmak, M., 2008. Influence of biaxial stretching mode on the crystalline texture in polylactic acid films. Polymer, 49(24):5344-5352.

Ou, X. and Cakmak, M., 2010. Comparative study on development of structural hierarchy in constrained annealed simultaneous and sequential biaxially stretched polylactic acid films. Polymer, 51(3):783-792.

Ouchi, T., Ichimura, S., and Ohya, Y., 2006. Synthesis of branched poly (lactide) using polyglycidol and thermal, mechanical properties of its solution-cast film. Polymer, 47(1):429-434.

Pauck, R. and Reddy, B., 2015. Computational Analysis of the Radial Mechanical Performance of PLLA Coronary Artery Stents. Medical Engineering \& Physics, 37(1):7-12. 


\section{ACCEPTED MANUSCRIPT}

Perego, G., Cella, G. D., and Bastioli, C., 1996. Effect of molecular weight and crystallinity on poly (lactic acid) mechanical properties. Journal of Applied Polymer Science, 59(1):37-43.

R Core Team, 2017. R: A Language and Environment for Statistical Computing, R Foundation for Statistical Computing, Vienna, Austria. https://www.r-project.org/.

Serruys, P. W., Chevalier, B., Sotomi, Y., Cequier, A., Carrié, D., Piek, J. J., and Helqvist, S., 2016. Comparison of an everolimus-eluting bioresorbable scaffold with an everolimus-eluting metallic stent for the treatment of coronary artery stenosis (ABSORB II): a 3 year, randomised, controlled, single-blind, multicentre clinical trial. The Lancet, 388(10059):2479-2491.

Serruys, P. W., Onuma, Y., Dudek, D., Smits, P. C., Koolen, J., Chevalier, B., and Windecker, S., 2011. Evaluation of the second generation of a bioresorbable everolimus-eluting vascular scaffold for the treatment of de novo coronary artery stenosis: 12-month clinical and imaging outcomes. Journal of the American College of Cardiology, 58(15):1578-1588.

Stoclet, G., Seguela, R., Lefebvre, J. M., Elkoun, S., and Vanmansart, C., 2010. Strain-induced molecular ordering in polylactide upon uniaxial stretching. Macromolecules, 43(3):1488-1498.

Tsai, C. C., Wu, R. J., Cheng, H. Y., Li, S. C., Siao, Y. Y., Kong, D. C., and Jang, G. W., 2010. Crystallinity and dimensional stability of biaxial oriented poly (lactic acid) films. Polymer Degradation and Stability, 95(8):1292-1298.

U. S. Food and Drug Administration, 2017a. FDA Investigating Increased Rate of Major Adverse Cardiac Events Observed in Patients Receiving Abbott Vascular's Absorb GT1 Bioresorbable Vascular Scaffold (BVS)-Letter to Health Care Providers. Retrieved from: https://www.fda.gov [Accessed 19 Feb. 2018].

U. S. Food and Drug Administration, 2017b. UPDATE on Increased Rate of Major Adverse Cardiac Events Observed in Patients Receiving Abbott Vascular's Absorb GT1 Bioresorbable Vascular Scaffold (BVS) - Letter to Health Care Providers. Retrieved from: https://www.fda.gov [Accessed 19 Feb. 2018].

U. S. Food and Drug Administration, 2016. FDA approves first absorbable stent for coronary artery disease [Press release]. Retrieved from: https://www.fda.gov [Accessed 19 Feb. 2018].

Vasanthan, N., Manne, N. J., and Krishnama, A., 2013. Effect of Molecular Orientation on the Cold Crystallization of Amorphous-Crystallizable Polymers: The Case of Poly (trimethylene terephthalate). Industrial \& Engineering Chemistry Research, 52(50):17920-17926. 


\section{ACCEPTED MANUSCRIPT}

Venkatraman, S., Poh, T. L., Vinalia, T., Mak, K. H., and Boey, F., 2003. Collapse pressures of biodegradable stents. Biomaterials, 24(12):2105-2111.

Zhang, X., Schneider, K., Liu, G., Chen, J., Brüning, K., Wang, D., and Stamm, M., 2011. Structure variation of tensile-deformed amorphous poly (L-lactic acid): Effects of deformation rate and strain. Polymer, 52(18):4141-4149. 